\title{
TOWARD A THEORY OF CONCEALMENT ${ }^{1}$
}

\author{
Maria S. Grigoryeva
}

New York University Abu Dhabi

October 11,2020

Word Count: 17,588 (text, references)

Corresponding Author: Maria S. Grigoryeva, Division of Social Science, New York

University Abu Dhabi, Abu Dhabi, United Arab Emirates, Email: mg5446

\footnotetext{
${ }^{1}$ I would like to thank Blaine Robbins, Paula England, Edgar Kiser, Ross Matsueda, Phi Hong Su, and the
} SRPP writing workshop participants for helpful comments and suggestions. 
TOWARD A THEORY OF CONCEALMENT

\begin{abstract}
Concealment, or withholding information from others, is of fundamental sociological interest.

Yet, a general theoretical framework of concealment is missing from the sociological cannon.

This paper specifies a model that builds upon, and moves beyond, existing accounts of concealment by emphasizing the desire for autonomy. I propose that desire for autonomy, and the subjective assessment of concealment as the best route to achieve autonomy, are necessary for individuals to attempt concealment. After specifying a dyadic model based on the concealer (ego) and the target of concealment (alter), I incorporate ego-alter power differentials as well as norms about privacy and concealment into a multilevel model of how concealment is initiated and maintained. The theoretical and empirical implications of this model of concealment are discussed.
\end{abstract}




\section{Introduction}

Concealment of information affects human interactions in a multitude of ways: whether we conceal or reveal information to others predicts power and dependence, affects trust and cooperation, precludes social influence, and determines what we know-and think we know - about other people (Shapiro 2005; Goffman 1959, 1963; Kitts 2003; Cowan 2014; Cowan and Baldassarri 2018; Talwar and Crossman 2011; Stattin and Kerr 2000; Rote and Smetana 2015; Jensen et al. 2004; Rossman 2014; Schilke and Rossman 2018). Likewise, when sociologists study fake news, hidden identities, norms about teen sex, structural holes, abortions, gaslighting, lending money to friends and family, wall street deception, internet privacy, and codes of the underworld, we are implicitly studying concealment (Burt 2009; Miller et al. 2003; Gambetta 2011; Cowan 2014; Simpson 2013; Marwick and boyd 2014; Mollborn 2017; Sweet 2019; Wherry et al. 2019; Guess et al. 2019).

Yet the body of empirical work in sociology that explicitly studies concealment, while innovative and growing, is small and fragmented (see Kitts 2003; Nippert-Eng 2010; Cowan 2014; Baldassarri and Cowan 2018; Grigoryeva 2018; Schilke and Rossman 2018). There are two interrelated reasons for this. First, a general theory of concealment in sociology has yet to be produced. The prevailing traditions addressing secret keeping or lying in sociology can be narrow, imprecise, tautological, and normative (Goffman 1959, 1963; Simmel 1905; Gottfredson and Hirschi 1990). A theory of concealment that parallels positivist frameworks found in sociological social psychology, such as theories of relational cohesion (Lawler and Yoon 1993; Thye et al. 2002) and social exchange theory (Emerson 1976; Cook 1987), would help clarify and resolve these outstanding problems. Second, within sociology and beyond, research on concealment is grounded in contradictory assumptions about human behavior, cognition, and embeddedness. Common terms like concealment, secrecy, and 
deception differ in meaning from one study to another. The empirical findings, consequently, are difficult to evaluate as a coherent body of knowledge, leading to fragmented and insular efforts at understanding concealment (Fales and Markovsky 1997).

In short, a general framework that would allow sociologists to theoretically ground emerging research and systematically accumulate knowledge about concealment is missing from the sociological cannon. Developing such a framework is the central goal of this paper. To highlight the conceptual diversity in the literature, I first take stock of common treatments of concealment in sociology. These include Goffman's dramaturgical approach to concealment $(1959,1963)$, concealment as a problem behavior (Stouthamer-Loeber 1986; Gottfredson and Hirschi 1990; Simpson 2013), and concealment as privacy (Nippert-Eng 2010; Anthony et al. 2017).

After taking stock, I build upon — and move beyond — these approaches to concealment by embedding them within a model that emphasizes the role of desire for autonomy. My model accounts for the empirical phenomena historically of interest to sociologists - concealment as performance, concealment as a problem, and concealment as privacy_while also explaining a broader range of behavior. In doing so, I highlight the desire to be self-directed with regard to others. I argue that the desire for autonomy, and evaluation of concealment as the best way to achieve autonomy, are necessary for individuals to attempt concealment. Once attempted, concealment becomes either partially or entirely successful depending on (a) the resources available to conceal, and (b) the interaction between the concealer of information (the ego) and the target of false or withheld information (the alter). I incorporate motivations of both egos and alters, ego-alter power differentials, and norms about privacy and concealment, as part of a novel synthetic model of how concealment is initiated and maintained. I finish with a discussion of the implications of my model and propose new directions for research. 


\section{Prior Theories of Concealment in Sociology}

What is Concealment?

The focus of the present paper is on any form of conscious concealment - the deliberate withholding of information from one or more people. This definition encompasses a wide range of behaviors and situations, such as selectively projecting non-verbal cues, obfuscated exchange, and collusion (Goffman 1959; Simpson 2013; Schilke and Rossman 2018). There is some debate about how to conceptualize different types of concealing behavior. Some scholars treat secrecy and lying as analytically distinct, on the grounds that (a) lying (an act of commission) generates false knowledge, while secret keeping (an act of omission) does not; or (b) that secrecy is more socially acceptable than deception (Gervais 2000). Other scholars distinguish between even more forms of concealment, including lying, avoiding discussion, omitting information, or disclosing only when asked (Rote and Smetana 2015).

Following Buller and Burgoon (1996), my focus is on concealment as a whole: the deliberate withholding of correct information, whatever the strategy of concealment, and the gap in the recipient's knowledge that arises as a result. In other words, I focus on the shared property of secrecy, omission, deception, and obfuscation, which is the act of intentionally denying someone knowledge of reality as you perceive it. ${ }^{2}$ The paper combines what we know about secret keeping, lying, and nonverbal deception, and uses the term concealment to refer to the total range of such behaviors. Given this working definition, I review prior theoretical treatments of concealment within sociology.

\section{Prior Theories}

\footnotetext{
${ }^{2}$ Whether omissions become secrets, or secrets become lies, is often situationally dependent. For example, things that are harder to conceal may require a false narrative to accompany concealment.
} 
There are three theoretical approaches in sociology that have influenced how sociologists study concealment. These include the dramaturgical approach, which conceptualizes concealment as the medium through which internal selves are presented to others (Goffman 1959; Goffman 1963); the problem approach, which conceptualizes concealment as antisocial behavior (Gottfredson and Hirschi 1990); and the privacy approach, which specifies concealment as an expression of ownership over information (Nippert-Eng 2010; Anthony et al. 2017). Below, I summarize and evaluate each way of thinking about concealment. Then, I pivot to an explanation that subsumes these three approaches under a general theory of concealment as autonomy seeking.

Goffman and the dramaturgical approach. Through his work on the presentation of self (1959) and stigma (1963), Erving Goffman's ideas about concealment have had, perhaps, the greatest influence on how sociologists have thought about secrets, lies, and other ways of managing personal information (Cowan 2013; Cowan 2014; Baldassarri and Cowan 2018; Kitts 2003; Rossman 2014). ${ }^{3}$ Like scholars in the Symbolic Interactionist (SI) tradition (Mead 1934; Thomas and Thomas 1928), Goffman is interested in how individuals use symbols to generate and maintain definitions of the social situation. For Goffman, because individuals communicate information via symbols of things - rather than things themselvesinformation can always be manipulated by an individual as they recast reality for others' consumption. Empirically, Goffman focuses on personal information, and the ways in which individuals control and repackage their unknown real (or "backstage") selves by enacting roles and defining social situations a particular way in view of others (or "frontstage"). Goffman outlines two main reasons for why individuals manipulate what others know about

\footnotetext{
${ }^{3}$ This brief overview cannot do justice to the breadth of Goffman's work and the scope of its influence on sociology. Thankfully, other scholars have offered reviews and critiques of Goffman's work, both as part of the SI cannon and beyond (e.g., Ritzer 1996).
} 
their backstage selves: reduction of personal costs (shame and stigma), and maintenance of a given definition of the situation. As Goffman writes:

"[the performer] has the capacity for deeply felt shame, leading him to minimize the chances he takes of exposure" (Presentation of Self, p. 243)

"The key factor in this structure is the maintenance of a single definition of the situation, this definition having to be expressed, and this expression sustained in the face of a multitude of potential disruptions." (Presentation of Self, p. 254)

Goffman treats the two motivations as interconnected. As people navigate their social worlds, they need (and want) to make sense of what is happening, how others will act, and what will happen next. Individuals, in other words, want to develop a stable definition of the situation. They do so by enacting (via looks, manners, behavior) certain narratives that—like in a play - allow everyone to know how to interact and what to expect. Individuals do not craft such narratives, but rather choose from a known set of scripts that are salient to the individual's role, social position, and the situation. ${ }^{4}$ Because deviations from scripts make social life unpredictable, unstable, and otherwise difficult, individuals who deviate from scripts are penalized by shame, lack of confidence, and stigma (Goffman 1959: 67; Goffman 1963). Therefore, when individuals "as they are" differ from the roles or scripts they "should be" performing, they conceal these differences to keep the performance predictable and appropriate, and to lessen costs to the self that would arise if the deviation was known. The audience - those who are perceiving the actor-have a stake in defining the situation, and will thus support the actor who enacts a script, often forgiving inconsistencies. At other times, however, the audience will actively seek to punish inept or incongruent performances.

To arrive at his definition of concealment, Goffman blends classic SI concepts with the work of Georg Simmel (1906, 1950). Several of Goffman's central propositions about how personal secrets are maintained, for instance, are taken directly from Simmel. Like

\footnotetext{
${ }^{4}$ Details of the script selection process are not provided, but Goffman offers a functionalist argument that essential roles and scripts are more likely chosen (Goffman 1959:27) and that individuals learn about the scripts via socialization (Goffman 1959: 73-74)
} 
Simmel, Goffman anchors on the notion that others can never truly know the entirety of an individual's motivations and goals, and that each individual acts as a gatekeeper between their innermost selves and society at large. Simmel and Goffman also both propose that secrecy and deception divide people into sociologically salient categories. For Goffman, the key division is the one that exists between the performer (manager of information) and the audience (those that depend on performers for information). Finally, Goffman's claim that information management serves to define social situations marries SI principles (Thomas and Thomas 1928) with Simmel's idea that relationships are defined by what the interactants do not know about each other.

Goffman's definition of concealment and disclosure as dramaturgy has generated both innovative scholarship and empirical support. Important research examining information spread and group-level dynamics directly draws on Goffman (Kitts 2003; Cowan 2014; Schilke and Rossman 2018; Cowan and Baldassarri 2018). By examining the link between socially sanctioned matters (e.g., abortion) and group-level beliefs, this work shows how concealing from certain others dampens dissemination of information, generates false consensus, and deepens existing social divisions at the group level (Kitts 2003; Cowan 2014; Cowan and Baldassarri 2018). In sum, empirical research at the forefront of sociological study of concealment is rooted in a Goffmanian framework. For the present theoretical model, I similarly draw on Goffman to specify links between norms, sanctions, and concealment, and individual ability to manipulate others.

Goffman's account of concealment, however, poses several theoretical issues, which I strive to address in my model. The first key issue is that Goffman's definition is imprecise, which makes the other issues harder to pin down. He equivocates, ${ }^{5}$ does not clearly outline

\footnotetext{
${ }^{5}$ For example, Goffman alternates between the claims that individuals follow routine or act strategically when concealing.
} 
the scope of his theory, and leaves key concepts and relations between concepts undefined ${ }^{6}$ (Miller 1986; Dawe 1973). This makes it difficult to operationalize and empirically test many of Goffman's propositions (Stryker 1980).

The second issue is that Goffman's take on concealment is functionalist, in that concealment serves the function of sustaining the social world as it is, while individuals manage themselves and their realities in order to buttress existing social structures (e.g., Goffman 1963:139; Collins and Makowsky 1972). Goffman's framework is therefore vulnerable to common critiques of functionalism, such as the inability to account for social change, or the exaggeration of consensus (such as Goffman's 1963 assertion that all actors strive to be "normal") (Cohen 1968). Claims of functionalism are particularly damning since, as I show below, concealment has decidedly nonfunctional components.

The third issue is that Goffman assumes that there is always a supply of concealable information. The goal of Goffman's theory is not to differentiate "honest" from "dishonest" communication, but rather to point out that all communication can be manipulated in some way toward upholding the status quo. ${ }^{7}$ This approach restricts the scope of study to manipulatable information, and is most salient to personal matters - those having to do with aspects of the self — because such matters are often impossible for alters to verify. Fittingly, Goffman tackles a subset of concealment, namely personal secrets. However, other types of matters may not be readily concealable. Departing from Goffman, I problematize access to concealable information: I do not assume that individuals always have unique access to the types of information that would allow them to gain control over a situation. Rather, I examine how social conditions may generate concealable information for certain individuals.

\footnotetext{
${ }^{6}$ For example, it is not clear how individuals are "socialized" into performances (e.g., Goffman 1963: 5-6, 109) or the differences between teammates and invested audience members (Goffman 1959: 77-105), or how we can determine the contents of the "norm" which actors aspire to.

7 Even when discussing stigmatized characteristics that cannot be concealed (discredited stigma), Goffman focuses on related but concealable aspects of the self, such as concealing of the stigmatized individual's true feelings about their stigma in front of others (1963).
} 
Finally, the role of the audience is underspecified. Audience members are alternately portrayed as passive and dependent on the performance, part of the performance, supporting the performance and/or contesting the performance, without sufficient explanation of when or why to expect any one of these audience reactions. I clarify how and why the roles of alters change as the concealment process unfolds.

Concealment as a problem behavior. A second tradition—rooted in assumptions largely orthogonal to Goffman's - treats concealment as a problem or pathological behavior. This tradition, which I call "concealment as a problem behavior", is explicitly theorized in Michael Gottfredson and Travis Hirschi's general theory of crime (1990). Gottfredson and Hirschi (1990) define concealment as a behavioral symptom of low self-control, which is a trait-like propensity for committing impulsive and self-centered acts. ${ }^{8}$ According to this definition, lying is neither premeditated nor deliberative. Rather, it is undertaken for easy and instant self-gratification, regardless of whether it is beneficial or sustainable outside of the immediate situation.

The main point of consensus between the "problem" and "dramaturgical" approaches to concealment — and one that is compatible with my model—is that concealment is done out of self-interest: for Gottfredson and Hirschi, concealment offers a way to obtain ends that are incongruent with others' interests. However, this is the only major agreement between the dramaturgical and problem-oriented views. In contrast to Goffman, concealment as a problem behavior is neither a way to control the self nor a way to obtain prosocial or functional ends. In fact, deception and concealment are defined as "impulsive" and "anti-social" by Gottfredson and Hirschi (1990: 93, 189). Another point of departure is that characteristics of the situation are irrelevant for Gottfredson and Hirschi's theory. No matter the setting,

\footnotetext{
${ }^{8}$ Individuals are born with low self-control and need to be socialized into controlling their impulses and taking others' interests into account in childhood, lest self-control stabilize into a trait that is largely immutable (Gottfreson and Hirschi 1990).
} 
situation, or circumstance, individuals with low self-control are expected to conceal more than individuals with high self-control.

Unlike the dramaturgical approach, Gottfredson and Hirschi's theory of low selfcontrol is precise and parsimonious; like the dramaturgical approach, their theory has strong predictive validity and broad empirical applicability (see Cullen et al. 2008 for a review). Similar treatments of concealment as impulsive, pathological, and even immoral, feature in psychology and economics (Stouthamer-Loeber 1986; Mazar et al. 2008; Ariely 2012). Moreover, of the three conceptualizations of concealment reviewed here, the problem approach is the only one that explicitly deals with secrecy and deception of personal and nonpersonal matters. ${ }^{9}$

However, I attempt to correct for three fundamental problems of this theoretical framework as it relates to concealment. First, like the dramaturgical approach, the problem approach provides a narrow definition of concealment. Not all forms of concealment are impulsive, antisocial, or executed at the expense of others. For example, deception in white collar crime is often self-interested but also planned, premeditated, and yields no immediate — but substantial future — benefits for the criminal (Geis 2000; Simpson 2013). Second, in underemphasizing characteristics of the situation, Gottfredson and Hirschi (1990) ignore many socially salient predictors of concealment, such as the presence of behavioral alternatives to concealment. In contrast, my model takes behavioral alternatives (and various incentives) into account. Third, most empirical research on concealment as a problem behavior suffers from circular analysis (Hahn 2011): the claim that concealment is a problem behavior in general is evaluated exclusively with regard to the concealment of problem behaviors (i.e., delinquency, theft, cheating). In other words, the problem thesis has been

\footnotetext{
${ }^{9}$ Concealment of personal matters may include keeping a secret about one's immigrant birth or hiding a speech impediment. Concealing insider information about stock performance would not constitute concealment of a personal matter.
} 
selectively tested within a narrow range of empirical cases that presuppose its conclusion. Similarly, in behavioral economics, concealment is conceptualized as a problem behavior, and operationalized as cheating and theft (Ariely 2012; Mazar et al. 2008; Michailidou and Rotondi 2019). Because the problem perspective is both logically flawed and influential, it has significantly biased the way concealment has been operationalized and measured. Widely used social surveys such as National Longitudinal Survey of Adolescent to Adult Health, place questions about lying in the same sections as questions about delinquency, running the risk of order and recency effects between concealment and anti-social behavior. ${ }^{10}$ In short, both theory and empirics of concealment as a problem behavior provide a biased and myopic view of the concealment process. In contrast, I argue that concealment is a broader phenomenon that lacks a clear normative valence: concealment can be either pro- or antisocial, or may be neutral with respect to the collective good, and can facilitate a wide range of behaviors and outcomes.

Concealment as privacy. A third and relatively new way of theorizing concealment is to approach concealment is an expression of privacy (Marx and Muschert 2007; Nippert-Eng 2010; Anthony et al. 2017). According to this tradition, privacy is defined as a legitimate or normatively prescribed denial of access to any aspect of a person, where the aspects of a person are treated as if they belong to that person (Baghai 2012; Nippert-Eng 2010; Anthony et al. 2017). Concealment as privacy, then, is the withholding of information about personal matters when such information can be conceptualized as belonging to someone (Anthony et al. 2017; Nippert-Eng 2010). Personal information can be thought of as a commodity like a house or the contents of a wallet: access to all three is dependent on ownership rights

\footnotetext{
${ }^{10}$ Normative considerations have also affected what we know about information management in less obvious ways. Disclosure of "important matters" has long been used as an empirical proxy for quality interpersonal relationships. Mario Small (2017) shows that, contrary to assumptions, individuals often disclose important, stigmatized, and emotionally charged matters to people whom they barely know, and conceal such matters from those closest to them.
} 
(Nippert-Eng 2010). Because you own personal information, your motivation to conceal can be expressed in terms of guarding and having control over what you consider to be yours.

By theorizing concealment as a way to demarcate information as personal property, the privacy approach (like the dramaturgical approach) focuses on socially prescribed concealment. This type of concealment both reflects and maintains existing social structures and ownership relations. This approach, in other words, best explains socially legitimated concealment with regard to an actor's own personal information (Nippert-Eng 2010). A key strength of the privacy approach is the acknowledgment of an association between legitimacy, capitalism, ownership rights, and information management (Baghai 2012; Anthony et al. 2017). Following the literature on privacy, I incorporate the relationships between privacy, power, resources, and concealment into my model.

In departing from the privacy approach, I argue that concealment and privacy are distinct concepts, and that concealment includes phenomena that cannot be explained as privacy or motivated by privacy considerations. Consistent with treatments in both sociology and law, I define privacy as the normative or socially legitimate barrier of access to the self (Baghai 2012; Anthony et al. 2017). Privacy rules shape access to personal information. Examples of such rules are expectations that communication partners reciprocate disclosure, or normative prohibitions against asking an acquaintance to reveal their salary. Many types of concealment, however, are carried out for reasons other than preventing illegitimate access to the self. Getting caught cheating on an exam is not a violation of the cheater's privacy, but it is a case of forced disclosure. In other words, ownership relations and legitimacy of control are the key distinctions between concealment and privacy.

To help clarify the distinction even further, concealment and privacy can be represented as a Venn diagram with shared and unshared areas. When someone takes another's apple, privacy is violated but nothing is concealed and nothing is disclosed. Lying 
about one's age to get into a bar and getting caught is not a violation of privacy but a disruption of concealment. Keeping a secret about one's sexual preferences constitutes both concealment and privacy. In sum, the concealment-as-privacy explanation both unduly narrows the range of behaviors that can be considered concealment, and conflates two analytically distinct concepts. I depart from this view, and specify the relation between privacy and concealment in more detail when I present my theoretical model.

\section{A New Theory of Concealment: Concealment as Autonomy Seeking}

Each of the three theoretical frameworks outlined above have significantly contributed to our understanding of concealment. We know that individuals are motivated to avoid stigma, get what they want, and preclude others from accessing private information (Goffman 1959, 1963; Gottfredson and Hirschi 1990; Nippert-Eng 2010), but that individuals may also disclose information because they believe that concealment is wrong (Ariely 2012). We also know that concealment is executed in reference to others (Goffman 1959; 1963; Nippert-Eng 2010; Cowan 2014). And we know that knowledge denied as a result of concealment affects dissemination of information and perceptions of reality at the group level (Kitts 2003; Cowan 2014).

Yet the weaknesses of each framework invite a reframing of existing theoretical approaches to concealment. The central goal of my paper is to put forth a theory of concealment that can both account for the empirical reality described by the dramaturgical, problem, and privacy approaches to concealment, and move beyond each to specify a more general, testable model of concealment.

I start by grounding concealment in a desire for autonomy. I propose that when individuals conceal in order to define a situation for others, to do something illegal, or to keep private information from others, they are motivated to gain autonomous control over a matter. The concept of autonomy is broader than the dramaturgical, problem, and privacy 
approaches, but it also complements each tradition's framing of concealment. The shared property among the three traditions and the newly proposed autonomy approach is social control. The three traditions focus on ego's concealment as a way to control other people, either by defining the situation a particular way, by acting against the wishes of others, or by denying others' access to personal information. In highlighting autonomy, I focus on an individual's desire to reduce social control over the self (Desi and Ryan 1985b; Reindal 1999; Ryan and Deci 2006; Dove et al. 2017). In other words, I view concealment as a process by which individuals attempt to gain freedom from the control of others (Stattin and Kerr 2000; Jensen et al. 2004). Because control over others and control over the self are interrelated (Lammers et al. 2016), my theory complements existing accounts, even as it shifts and expands the theoretical focus.

To propose a wide-ranging model of concealment, I incorporate concepts and findings from research across the social sciences. While there are interdisciplinary differences in which elements of concealment are considered essential, all existing definitions of concealment feature at least one of four elements: intent, behavior, interaction, and information gaps. First, social scientists typically view concealment as intentional, in the sense that individuals are aware of their ability to conceal and elect to do so based on a set of criteria (Ajzen 2005; Talwar and Crossman 2011; Slepian et al. 2017; Gneezy 2005). ${ }^{11}$ Mistakenly withholding information, or doing so compulsively, is not defined as concealment by most traditions that view concealment as intentional. Second, the majority of research on concealment stipulates that concealment manifests as behavior. Attempting to withhold accurate information, either on its own or in combination with actively providing false

\footnotetext{
${ }^{11}$ Intent has been used synonymously with desire (Slepian et al. 2017) or both desire and evaluation (e.g., Gneezy 2005). Types of intent include altruism, utilitarianism, self-interest, and harm-avoidance among others (Erat and Gneezy 2012; Goffman 1959; Bueller and Burgoon 1996).
} 
information, constitutes the behavioral manifestation of concealment (Gottfredson and Hirschi 1990; Talwar and Crossman 2011; Mazar et al. 2008; Ariely 2012).

Third, concealment is fundamentally relational, and emerges from social interaction between individuals (Cowan, 2014; Simmel 1950). Both the ego and the alter enter an interaction with a variety of goals and motivations, which can change and be renegotiated as the interaction unfolds. Concealment emerges from, and is embedded within, these exchanges (Goffman 1959; Buller and Burgoon 1996; Affifi et al. 2005). Fourth, concealment generates information gaps between the seeker (alter) and sender (ego) of information. Simmel (1906) highlighted the ability of secrecy and concealment to generate inequalities in access to knowledge. Drawing on Simmel's propositions about concealment as differentiation, as well as Goffman's work on stigma, contemporary research in sociology focuses on the information gaps that arise as a result of concealing stigmatized matters (Simmel 1950; Kitts 2003; Cowan 2014). To situate my theory within general research on concealment, I model concealment as a social process that is initiated by a desire for autonomy, and consists of intentional, behavioral, relational, and information-limiting components. In short, I propose a broad synthetic model of concealment.

I also aim for precise definitions of constructs, explicit assumptions and scope conditions, a parsimonious theoretical framework, and logically consistent and testable propositions (Cohen 1980; Bacharach 1989; Fales and Markovsky 1997; Suddaby 2010). To that end, I start by laying out my assumptions. I then define the key constructs and propose a model of concealment at the dyadic level. Next, I introduce group level factors that contextualize the dyadic model. I finish by delineating the scope of my model, and discussing its implications for concealment research.

Concealment is modeled as a process that can be divided into two phases. During the first phase, passive possession of information becomes attempted concealment. During the 
second phase, attempts at concealment become successful. During the third phase, successful concealment ends. I first lay out a dyadic model that incorporates the ego and the alter, and then embed my dyadic model in a larger social context via norms, stigma, privacy, and power.

\section{Model of Concealment as Autonomy Seeking}

My model ultimately explains successful concealment: one actor intentionally keeping information unknowable to another actor. I propose that when an individual desires autonomy, and evaluates concealment as the most effective way to gain autonomy, then the individual will attempt to conceal information. An attempt that is skillful and resourceful will result in successful concealment. The process is illustrated in Figure 1.

\section{[ Figure 1 about here ]}

The model of concealment as autonomy seeking rests on several assumptions, which I review below.

\section{Assumptions}

1. Two actor assumption. The model assumes 2 types of actors. The first actor is the ego, who intends and initiates concealment. The second actor is the alter, who is the intended recipient of ego's concealment. The model does not assume that the alter is a seeker of information, since they may not know enough to be actively seeking.

2. Decision-making assumption. Individuals make decisions both slowly and deliberately as well as quickly and automatically, with these two general cognitive processes often interacting to produce action (Dijksterhuis et al. 2006; Evans 2008; Gilovich and Griffin 2010; Lizardo et al. 2016). ${ }^{12}$ Deception, and other forms of

\footnotetext{
12 This dichotomy is useful but not completely accurate (Stanovich 2011). Rather, in thinking fast, individuals can be engaging in multiple distinct cognitive processes, such as associative processes, or habit-like processes that used to be deliberative but have been automated overtime (Gilovich and Griffin 2010; Kahneman, 2011). Similarly, automatic and unconscious processes may also be deliberative and slow (Dijksterhuis 2006), and creative processes may involve multiple types of cognition (Gilovich and Griffin 2010).
} 
concealment, appear to constitute "slow" ways of thinking (Gombos 2006). Multiple studies have shown that withholding information requires executive control (Gombos 2006; Vrij and Mann 2001; Talwar and Lee 2002). When we engage executive control, we tend to think "slowly": executive control is characterized by directed attention and inhibition of inappropriate responses, and generates problem solving and planning (Gombos 2006; Baddeley 2000). In terms of concealment, individuals consider rewards, sanctions, and situational opportunities in deciding and planning concealment (Talwar and Crossman 2011; Gneezy 2005; Erat and Gneezy 2012; Affifi et al. 2005; Ariely 2012). Individuals also alter their strategy based on new information, artfully control their own behavior, and act based on evaluations about how others see the world (Talwar and Lee 2002; Vrij and Mann 2001; Affifi et al. 2005). In other words, concealment is a behavior that is produced and maintained via executive control. To put into pragmatist terms, concealing information is often done by actors facing problematic situations where self-reflection and evaluations are salient, and habitual and automatic ways of thinking may be blocked (Dewey 1922; Mead 1934; Matsueda and Grigoryeva 2014).

Therefore, I posit that the individual decision to conceal is made consciously and deliberatively. However, I do not assume that decision-making adheres to the standard economic model (SEM; e.g., Becker 1998). Rather, following research in cognitive psychology, I assume that even deliberative decision-making departs from both SEM and Bayesian updating processes via the use of heuristics, the influence of mood and emotions, the instability of preferences, and framing (e.g. Kahneman and Tversky 1979; Schwarz 1990; see Gilovich and Griffin 2010, for a detailed review). This view is consistent with analytical sociology and the DBO (Desires, Beliefs, 
Opportunities) approach I adopt in the present manuscript (Hedstrom 2005; Hedstrom and Bearman 2009).

I thus assume that actors (both the ego and the alter) interact intentionally with the situation by choosing behavioral options based on their desires, beliefs, and opportunities (Hedstrom 2005). ${ }^{13}$ Beliefs are propositions about the world which the actor holds to be true, desires are wishes of the actor, and opportunities are the alternative lines of action available to the actor (Hedstrom 2005: 38-39). I revisit this assumption, and what relaxing it means for my theory, in discussing the scope conditions of my model.

3. Communication assumption. Following Buller and Burgoon (1996), I assume that concealment is a subset of communication between the ego and the alter.

Communication is an exchange of symbols (usually verbal, but sometimes unspoken), which have meaning for both the ego and the alter (meanings that are not necessarily shared between the ego and the alter, but must have some minimal alignment) (Buller and Burgoon 1996). I consider a verbal exchange between two people as the prototypical context for concealment, and lay out theoretical elements as part of a dyadic model, with the understanding that this can be expanded to include other modes of communication and an increasing number of participants.

\section{Part 1. Explaining a Concealment Attempt}

The first part of the model explains ego's attempts at concealing information. A concealment attempt is a deliberate effort on the part of the ego to keep information about a matter unknowable to an alter via omission, obfuscation, secrecy, or deception (among other strategies). There are two necessary and sufficient conditions for attempting concealment:

\footnotetext{
13 The DBO model is consistent with both learning theories and dual-process models of decision making (Hedstrom 2005). For example, research shows that automatic decision-making processes tend to yield results similar to what we would expect under the DBO model (Dijksterhuis et al. 2006).
} 
ego's desire for autonomy, and ego's evaluation of concealment as the most effective way to obtain autonomy.

Initial condition 1. Ego desires autonomy. I define autonomy as the subjective ability to decide and enact behavior with regard to a matter, free from the control of an alter. To gain autonomy, the ego must decrease alters' control over them. Control can be expressed in many ways, including alter's emotional reactions toward ego, alter's appraisals of ego, alter's manipulation of the relationship between ego and alter, and any other interventions by alter that contests ego's control over a matter. A matter is defined broadly as any behavior, comportment, relationship, goal, experienced emotion, or belief about something. In other words, an increase in ego's autonomy over a matter vis-a-vis the alter, by definition, necessarily decreases alter's control over the ego. This means that my definition of autonomy excludes mastery and self-determination over a matter that is achieved without reference to others. For example, figuring out how to start a fire and keep oneself warm while camping alone involves mastery over the elements, but does not constitute gains in autonomy.

Autonomy has been conceptualized as a property of individuals (Deci and Ryan 1985b), network positions (Burt 1980), groups (Simmel 1950), and social fields (Fowler 2006). Debates concerning the individuating properties of autonomy, and whether autonomy is useful in studying individuals as embedded social actors, abound (Reindal 1999; Deci and Ryan 2006; Dove et al. 2017). To reign in this term conceptually, and to make it logically consistent with the present model, I focus on situational autonomy: subjective autonomy that is targeted at a specific person(s) and matter(s), rather than autonomy with respect to all persons and situations that constrain individual choice (e.g., Deci and Ryan 2006). In this way, I focus on autonomy and autonomy desire as bound to specific relationships and situations, rather than autonomy as an asituational general human need (Chen et al. 2015). Doing so increases the analytical clarity of autonomy as a concept, bolsters the falsifiability 
of my model, and lends itself to integration with pragmatist conceptions of the situation. It also leaves open the possibility that the actor who gains autonomy from a certain alter in one respect, can simultaneously experience control from other alters, or be controlled by the same alter but with regard to a different matter. To say that a university student is free of parental influence or control says nothing about the student being controlled by peers, professors, or societal gender norms. In fact, my model explicitly stipulates that even as they seek situational autonomy, many individuals follow socially prescribed standards of conduct.

Several properties of situational autonomy have implications for my model. First, perceptions of autonomy are not necessarily tied to one's moral values or judgments (Ryan and Desi 2006). One can feel autonomous in choosing and enacting behaviors that have no moral salience, or may even contradict one's core moral judgements. Second, autonomy can vary in magnitude: an individual can have no autonomy, some autonomy, or complete autonomy with respect to a matter and an alter.

Third, autonomy can be desired instrumentally as a means-to-an-end or for its own sake. Fourth, autonomy is not always desirable. For example, if your goal is to learn something from an expert in the field (e.g., working with a fitness coach to increase your running endurance), then you will likely submit voluntarily to their control. While some individuals prefer autonomy more than others across situations (Desi and Ryan 1985a), autonomy desire is also a function of a particular situation: Desire for autonomy will be assessed based on features of the exchange between the alter and the ego, such as alter competence, conflicts of interest between ego and alter, and how important or essential the matter is to the ego. Desire for autonomy will also depend on other factors, such as legitimacy of power structures and norms about privacy, which are described in the group processes section. Fifth, experienced autonomy and desire for autonomy are negatively related. This is because the less autonomy someone has, the greater the likelihood that their 
ideal autonomy exceeds their experienced autonomy, leading them to desire more autonomy. Additionally, even if there are no differences between autonomy goals and experienced autonomy, it can still be desirable to maintain a given level of autonomy. In my model, desire for autonomy acts as a catalyst, initiating an evaluative process by which individuals determine the best way to obtain their desired degree of autonomy (path 1 in Figure 1). For a detailed overview of autonomy research, please see Appendix A.

Initial condition 2. Ego evaluates concealment as the most effective way to obtain autonomy. As outlined in Assumption 2, individuals make subjective evaluations of whether to conceal based on their beliefs about themselves and others, their desire for autonomy and autonomy-related outcomes, and the opportunities for concealment. Ego's desires, beliefs, and opportunities are thus informed by the following five conditions: ${ }^{14}$

1. Unique access to relevant information. To initiate concealment, ego must believe that alter is ignorant of matter Y. Because ego's unique access to information is a precondition for concealment, my model specifies that information asymmetries exist prior to concealment and are not necessarily created through concealment. Rather, concealment exploits preexisting information asymmetries in ways consistent with seeking autonomy. This is an important distinction from definitions of concealment as generating information asymmetries (e.g., Goffman 1959).

2. Alternatives for obtaining autonomy. Concealment is one method of gaining autonomy. Alternative methods for gaining autonomy include ego exiting the relationship with alter (Hirschman 1970) or overt ways of gaining autonomy (e.g., physically overpowering the alter).

\footnotetext{
${ }^{14}$ Concealment may not be enough to achieve complete autonomy with regard to an alter and matter. Presumably, if one had complete autonomy, concealment would be unnecessary. However, concealment can increase one's autonomy within the situation, and potentially lead to complete autonomy (and revelation or abandonment of the secret) in the future.
} 
3. Perceptions of the alter's desire and ability to exert control over the ego. This condition refers to ego's beliefs about how the alter will use the concealable information. In order to attempt concealment with regard to matter Y, ego should believe that if the alter were to obtain information about $\mathrm{Y}$, alter would be willing and able to control ego. For example, an expectation that an employer is willing and able to withhold promotion based on a pregnancy would prompt an employee to conceal a possible pregnancy.

4. The costs and benefits of concealment. Costs include moral, normative, contractual, or legal sanctions against lying (Ariely 2012; Gervais et al. 2010), as well as the emotional and cognitive strain of concealing information (Bueller and Burgoon 1996; Slepian et al. 2017). Costs to concealment can motivate an ego to choose alternative means of becoming autonomous, or to disclose information even at the risk of losing autonomy over a matter. For example, exposure to norms against lying may increase an individual's propensity for honesty, to avoid being labeled a liar (Ariely 2012; Gervais et al. 2010). On the other hand, situations that consistently reward concealment increase the likelihood that ego will attempt to conceal. To illustrate, children who are enrolled in schools where lying allows them to evade corporal punishment are more likely to lie (Talwar and Lee 2011).

5. Likelihood of concealment success. In deciding whether a concealment attempt will successfully preclude alter's knowledge, ego appraises their own skill at concealing relative to alter's skill at detecting concealment, as well as other circumstances that may determine success (such as alter's access to alternative sources of information). Perceiving concealment as having a high probability of 
success will increase the likelihood of attempting concealment (paths 3 and 4 in Figure 1).

Taken together, the two conditions (paths 1 and 2 in Figure 1) produce a concealment attempt:

Proposition 1. If ego desires autonomy and evaluates concealment as the most effective means of gaining autonomy over matter $\mathrm{Y}$, then ego will attempt to conceal information about $\mathrm{Y}$ from the alter.

It is important to note that the process behind a concealment attempt critically depends on the decision-making of ego. While an alter can influence ego's desire for autonomy and/or ego's evaluation of concealment as an effective strategy, any effects of alter on ego's concealment attempt are conditional on ego's perceptions, motivations, and appraisals (as indicated by the dotted line of path 3). In other words, alters cannot spur egos' attempts at concealment independently of ego desire and decision-making. An alter sanctioning an ego over matter Y (e.g., having an abortion), for instance, brings about concealment if and only if (a) the ego desires to be free from alter's sanction, and (b) the ego determines that concealing matter $\mathrm{Y}$ is the best way to avoid the sanction.

This is not to say that alters are inconsequential to ego's decision-making. Ego and alter often mutually participate in defining a situation as conducive to concealment. A parent and a child, for example, may jointly arrive at an agreement (or disagreement) over teen sex, such as "have sex as long as it's safe and consensual" or "if you are having sex, I want to know about it" or "no sex until marriage". These (dis)agreements impact whether and how adolescents go about concealing sexual activity from their parents (Schalet 2011). However, the necessary desire for autonomy and the decision to conceal still reside with the ego; an alter will often be ignorant of the impact their actions have on ego's concealment. As I show later on, the features of alters and ego-alter relationships that are most salient for autonomy 
desire and decisions to conceal—such as conflicts of interest, expectations about sharing information, or alter ability to sanction ego — depend on three general phenomena: power, privacy, and stigma.

\section{Part 2. Explaining Successful Concealment, Given an Attempt}

Desire for autonomy and favorable evaluations of concealment produce concealment attempts. A concealment attempt, however, does not guarantee success. I define concealment as successful to the extent that attempted concealment results in alter's ignorance over matter Y for ego's intended period of time. In other words, concealment has a temporal dimension, where the ego intends, and attempts, to conceal information for a specific time period. My model does not place limits on ego's intended period of concealment, with "for now" and "forever" serving as valid time frames. Likewise, the ego can update the intended duration of a concealed matter at any point in the concealment process. As a result, the duration of a successful concealment can be relatively short (such as planning a surprise party) or long (such as generations-long family secrets surrounding out-of-wedlock births in early $20^{\text {th }}$ century Ireland). Given some intended length of time during which the ego desires to keep the alter uninformed, there are two ways to evaluate the success of concealment.

First, success can be evaluated by how much of the intended period of concealment was characterized by alter's ignorance. The greater the proportion of alter's ignorance over a period of intended concealment, the more successful the concealment. In situations of wartime occupation, if the goal is to maintain secret correspondence with allies for the entirety of a war, the ability to conceal correspondence for one year may be interpreted as more successful than the ability to conceal for one week. Second, success can also be evaluated as a nominal outcome: whether ego achieves the intended degree of autonomy given alter's ignorance. If a teen intends to attend a party one week from today — and she wants to keep it a secret from her parents - the difference between keeping the secret for five 
or six of the seven days is meaningless, since neither option would result in successfully attending the party. Success in this example is determined by whether the teen was able to keep the secret long enough to attend the party without her parents knowing.

At the dyad level, I focus on three factors that determine whether an attempt at concealment is successful: the skill of the ego, the skill and awareness of the alter, and the opportunities and resources available to ego and alter (paths 6 and 7 in Figure 1).

The role of the ego. The success of concealment depends on ego's skill at maintaining alter's ignorance (path 6, Figure 1). I define concealment skill as ego's ability to keep information unknowable. This skill requires ego to have a developed theory of alter's mind - an understanding of how the alter interprets information, and what they find plausible (Talwar and Lee 2002). Ego's skill also requires the ability to withstand the cognitive burdens that accompany the creation and maintenance of false narratives, such as (a) controlling "leakage", or the unanticipated inconsistencies that emerge as a result of concealment; (b) precluding alter from accessing other information sources; (c) withstanding alter's attempts at deciphering concealment; and (d) maintaining ongoing narratives of concealment over time (Buller and Burgoon 1996). Thus:

Proposition 2. If ego has sufficient skill to preclude (a) leakage of information to the alter, (b) attempts made by alter to detect information, and (c) alter access to other sources of information, an attempt at concealment will be successful for some amount of time.

The role of the alter. Thus far, I have focused on ego's preferences, decision making, and behavior. Alters, however, can independently affect whether concealment takes place by disrupting the link between attempt and success (path 6, Figure 1). I model alter's role as follows. Alters must first suspect that information is being withheld. A number of factors, including prior history with concealment, trust toward ego, and noticing inconsistent 
information can induce suspicion. Suspicion can also have more systemic sources, such as conspiracy theories stemming from state mistrust (Boltanski 2014). Second, alters must decide whether to act on their suspicion. The decision to act depends on the alter's willingness and desire to know what is being concealed. Willingness to know is determined by whether the alter considers the information being withheld as private, and whether the alter deems the hidden information to be useful, interesting, or damaging to themselves or others. Given suspicion and willingness to know, alters will then engage in detection of leakage, attempt to seek out alternate sources of information, confront the ego, or take a number of other actions that affect the success of a concealment attempt (Buller and Burgoon 1996). ${ }^{15}$ After an attempt at concealment, the interplay between alters and egos may take the form of a game, with the alter attempting to know and the ego attempting to evade (Shapiro 2005). Proposition 3 specifies the alter's role:

Proposition 3. Alter's suspicion, desire to know, and skill at detecting concealment decrease the success of a concealment attempt.

The role of opportunities. Opportunities and resources available to assist the ego in concealing information will impact the success of a concealment attempt (via path 7 in Figure 1). Following a large literature on how structural opportunities constrain and enable action (e.g., Cohen and Felson 1979; Hedstrom and Bearman 2009), I propose that opportunities increase the success of concealment. Resources and opportunities that affect success include ego's placement in informational brokerage positions (Burt 2009; Simpson 2013), frequency of communication, availability of plausible alternative narratives, and settings which help an ego learn how to conceal - thereby increasing their concealment skill (Buller and Burgoon 1996; Talwar and Lee 2011). Thus:

\footnotetext{
${ }^{15}$ Suspicion can occur without concealment having taken place. In other words, alters can wrongfully suspect ego concealment.
} 
Proposition 4. Structural opportunities and resources that support ego's skill at concealment relative to alter's skill at detection, increase the success of a concealment attempt.

Additionally, resources and opportunities allow the ego to anticipate the likelihood of success, indirectly increasing concealment attempts by ego (path 3 in Figure 1). The availability of opportunities and resources vary according to actors' access to power and information, and their embeddedness in institutions that define, reward, and punish modes of behavior, ability to control others, and information management. Later on, I discuss several ways in which meso- and macro-level social processes inform the specific opportunities and resources available to egos and alters.

\section{Part 3. Ending Concealment}

Because I conceptualize concealment as a potentially finite process, it is useful to define how it ends. There are two ways for concealment to end. First, concealment ends when there is a change in the behavior of ego, such that ego willingly and successfully discloses information that was previously concealed. ${ }^{16}$ In his book Someone to Talk To, Mario Smalls (2017) examines individual decisions about disclosing information to alters. He finds that decisions to disclose depend on a number of factors: the pool of available confidants, the ego's expectations about the alter's capacity for empathy, and characteristics of the immediate situation such as ego's readiness to reveal the information while in the presence of a potential confidant (Small 2017; see also Slepian and Kirby 2018). Second, despite the desires and decisions of the ego, concealment can end when actions on the part of the alter, third parties, or uncontrolled "leakage" of information reveal information to the alter.

\footnotetext{
${ }^{16}$ Disclosure of concealed information should be successful for concealment to end because, in the case of attempted but unsuccessful disclosure, information remains unknowable as a function of initial success of concealment. In that sense, some concealments are irreversible: the ego does not always get a chance to reveal the concealed information, even if they want to.
} 
Proposition 5. Concealment ends when the alter learns of ego's concealed information.

To summarize, concealment is a process that implicates two types of individuals - the ego and the alter, and depends on the ego's desire for autonomy, the interactions between the ego and the alter, and the resources available for carrying out concealment. Concealment is an intentional behavior: it is motivated by an evaluation of the best way to become autonomous from the alter. Despite specifying the ego as a focal actor in the first phase of the concealment process, my model is fundamentally relational. Concealment is decided and attempted with reference to the alter, and its success depends on the interactions between the ego and the alter, as well as the alter's willingness and ability to detect concealment. Finally, I argue that concealment is only a viable source of autonomy when the alter is already ignorant of information. Therefore, concealment does not generate information asymmetries per se, but, rather, successful concealment maintains and channels alter's ignorance in ways that are consistent with ego's desire for autonomy.

\section{Group-Level Propositions}

The model specified in Figure 1 operates at the dyadic (or relational) level. In this model, the ego and the alter appear to interact beyond — or outside of — social context. Yet, the ability and willingness of the alter to control the ego, the availability of alternatives to concealment, and the very desire to be self-directed all depend on the social context in which the ego and the alter are embedded. Thus, the model in Figure 1 is incomplete. I argue that meso- and macro-level processes are crucial to our understanding of whether individuals pursue concealment and if concealment will be successful. Below, I endogenize the desire for autonomy, the evaluation of concealment as an effective strategy, and the opportunities for concealment, and propose ways in which meso- and macro-level social processes affect concealment at the dyadic level. Then, I present a full model of concealment that accounts for 
cross-level relations (Figure 2). I discuss whether, and how, four group-level factors impact an individual's desire for specific autonomy: privacy, power, sanctions (including stigma), and the cultural dimension of individualism-collectivism.

\section{Privacy and Concealment}

Building on recent scholarship (Baghai 2012; Anthony et al. 2017), I define privacy as the legitimate barriers that keep one actor from accessing properties of another actor. Privacy can extend to a variety of ownership relations (Nippert-Eng 2010), but here I focus on the types of privacy that relate to information. To the extent that certain matters are considered private or the ego is entitled to privacy, alters do not have the right to access personal information in possession of ego. In such situations, the ego's autonomy is normatively approved and encouraged. Privacy designations specify what ought to be someone's to control, and also who ought to have control over a matter. Privacy designations can affect an individual's actual and desired autonomy, as well as their access to concealable information.

I outline a number of channels through which privacy rules impact concealment. First, privacy designations may increase the desire for autonomy (path 8 in Figure 2). Matters that are socially defined as private should increase an ego's desire for autonomy because there are social—and sometimes legal—incentives for having independent control over the matter. For example, at least part of people's desire to preclude others from regulating their sexual behavior stems from the social definition of adult sex lives as private. In other words, privacy labels make autonomy over a matter more socially accepted and expected, increasing the possibility that individuals will conceal information with regard to the private matter.

Second, because privacy refers to socially legitimate denial of access and control, matters that are considered private enjoy both institutional and individual support in being kept from others. In this way, privacy designations render information more concealable 
(path 10 in Figure 2). For private matters, institutions and individual actors increasingly reward concealment attempts and skills, and create opportunities that increase the success of attempted concealment. Likewise, disclosure with regard to private matters may be penalized or made more difficult. Organizations that define earnings as private, for instance, refrain from making salaries public, and explicitly forbid workers to share information about how much they earn.

Third, individual access to privacy—which is unequal—will impact ego's ability to conceal. Given a definition of a matter as private, those actors who are afforded less privacy will desire more of it (path 8 in Figure 2). This is because for those individuals, autonomy is both socially rewarded and unfulfilled, leaving a gap between ideal autonomy and realized autonomy. In other words, "public people" (those who are not afforded privacy) with private matters (those matters which are, on average, considered private) will desire autonomy the most. Propositions 6 through 8 specify the effect of privacy on concealment:

Proposition 6. Actors are more likely to desire autonomy over matters that are defined as private.

Proposition 7. Matters defined as private will be allotted greater resources and opportunities for concealment.

Proposition 8 . Actors who are not afforded privacy over a matter collectively viewed as private will desire autonomy more than those afforded privacy.

In sum, privacy designations affect how much people desire autonomy, which is a necessary condition for concealment. Likewise, because concealment is a way to enforce privacy, matters defined as private will be disproportionately allotted social, structural, and legal resources and rewards that facilitate concealment.

Power and Concealment 
Following Emerson (1962), I define power as a property of the relation between actors, where one actor's dependence grants another actor the power and ability to coerce (Weber 2009). Research in deviance and social control suggests that powerful groups assert and maintain control over less powerful groups by defining conduct in a way that disenfranchises and controls the less powerful (Reinarman 1994). There are many examples of the link between powerlessness and social control, including laws and norms targeting behavior of disadvantaged or marginalized populations, such as differential punishment for possession and distribution of cocaine and crack (Becker 1963; Beckett 1997; Alexander 2010; Adler and Adler 2012), or the general lack of self-directedness afforded to those in positions of lower power (Wacquant 2009). I propose that power imbalances among actors in a dyad, and among social groups more generally, affect egos' desire for autonomy (path 8 in Figure 2). To the extent that individuals in positions of low power are subject to increased social control, they will increasingly desire autonomy. Matters associated with low power individuals, as well as behaviors and characteristics of low power individuals irrespective of the matter, are subject to greater control by others. In short, less powerful individuals are more likely to desire autonomy because they possess less of it. Thus:

Proposition 9. Decreases in power increase the desire for autonomy.

Power also affects whether concealment will be evaluated as an effective strategy for gaining autonomy (path 9 in Figure 2). Power affords alternative ways of gaining autonomy vis-à-vis other actors. Powerful egos have greater independence relative to the alter and/or greater access to alternative exchange partners (Emerson 1962). This allows an ego to limit alter's control in ways other than concealment (e.g., by exiting the relationship). To state it differently, alternative exchange partners increase the odds that concealment will not be evaluated as the most effective means of gaining autonomy. Thus: 
Proposition 10. Decreases in power increase the likelihood that egos select concealment as a means of gaining autonomy.

Propositions 9 and 10 show that increases in power reduce the likelihood that individuals attempt concealment. However, via another causal path (path 10 in Figure 2), power increases both the likelihood of attempted concealment and its success. This is because power affords an ego greater resources and opportunities for concealment. For example, powerful public individuals often employ a team of public relations experts who are tasked with concealing unwanted information. Access to resources also allows powerful egos to increasingly anticipate successful concealment, increasing the likelihood of concealment attempts.

Proposition 11. Increases in power increase the likelihood of a concealment attempt via ego's expectations of success.

Proposition 12. Increases in power increase the likelihood of successful concealment, via greater opportunities for ego to conceal.

Finally, the proposed relationships between power and concealment may depend on powerdistance and legitimacy of power (Hofstede 1980). The more legitimate a power-imbalanced relationship, the more likely the high-power actor will seek increased or total autonomypotentially increasing their propensity to lie — and the less likely the low-power actor will desire autonomy and seek out concealment (Heyman et al. 2013)

In sum, I expect power to have countervailing effects on concealment. Power may decrease the desire for autonomy and decrease the likelihood that concealment is evaluated as the best way to gain autonomy, but power may also reduce the risks and increase the efficacy of concealment as a strategy for gaining autonomy. Legitimacy of the power structures may condition the effects of power on autonomy and concealment. 
Social sanctions surrounding certain matters_-including concealment itself_-impact concealment. First, matters that are stigmatized or illegal elicit desire for autonomy as a way to avoid social and physical sanctions (path 8 in Figure 2; Goffman 1959, 1963; Kitts 2003; Cowan 2014; Cowan and Baldassarri 2018). Under these conditions, egos are likely to conceal. Alters who are perceived to support and enforce the status quo will elicit ego's desire for autonomy over socially sanctioned (i.e., stigmatized, illegal) matters, because such alters are seen as willing to control the focal actions of others (e.g., by dispensing sanctions). Thus:

Proposition 13. Socially sanctioned matters increase ego's desire for autonomy, and the likelihood of concealment.

Second, informal and formal sanctions that specifically target lying, secret-keeping, and obfuscation introduce costs to concealment as a strategy (path 9 in Figure 2). Examples include legal injunctions to lying under oath, as well as the shame, stigma, and reputational costs associated with being labeled a liar. I propose that in the context of sanctions concealment becomes a costly strategy, decreasing concealment attempts. Thus:

Proposition 14. Social sanctions for concealing information decrease concealment attempts via negative evaluations of concealment as a strategy.

The additional proposed relationships (propositions 7 through 14), superimposed on the dyad-level model, are summarized in Figure 2.

\section{[ Figure 2 about here ]}

As Figure 2 illustrates, the concealment process at the dyadic level is dependent on the broader social context in which the ego and the alter interact. Designations of rights to information ownership, norms about whether and how individuals are to seek autonomy, and allocation of power predict concealment attempts and success. These factors also specify who 
will conceal, what matters will be concealed, and which concealment attempts will be successful.

Moreover, privacy, power, and sanctions are interrelated, producing compound effects on concealment. For example, rights of ownership (such as privacy) are often disproportionately allocated to powerful individuals. Likewise, powerful groups define what is and is not sanctionable (Adler and Adler 2015). While it is beyond the scope of the present paper to enumerate the ways in which these three phenomena interrelate to produce concealment, it is a worthwhile endeavor for future research.

\section{Individualist-Collectivist Settings, Autonomy, and Concealment}

Groups and cultures vary in how much importance is placed on the individual versus the collective, suggesting that actors in collectivist societies conceptualize themselves primarily as group members rather than individuals (Hofstede 1980; Markus and Kitayama 1991; Triandis 1995). These differences may impact actors' understanding of — and desire for-autonomy and concealment. The intuition here is that actors in individualist societies may have greater autonomy desire (and thus conceal more) than actors in collectivist societies. Yet, contemporary research shows that across individualist and collectivist societies, autonomy desire motivates action, and perceived autonomy is associated with greater life satisfaction (Chirkov et al 2003; Ryan and Deci 2006; Leotti et al 2010; Chen et al. 2015; Lammers et al 2016). Likewise, actors in individualist societies perceive gains to "group autonomy" as gains to personal autonomy at least as much as actors in collectivist societies (Kachanoff et al. 2019). However, there may be cultural differences in whether situational autonomy is desired in a given circumstance. For example, power-distance, which is a cultural value associated with collectivist societies that stresses the unequal distribution of power among group members, may affect when and with whom autonomy is desired (Hofstede 1980). 
Prior research also suggests that the collectivist-individualist distinction is not associated with differences in how much actors conceal, but may predict differences in the situations that invoke concealment (Triandis 2001). Fu et al (2007) find that children learn to conceal about matters that reflect cultural expectations. In their study, Chinese children were more likely to endorse lies that characterized them as a good member of the collective - such as being modest, while Canadian children were more likely to endorse lies that highlighted their individual accomplishments. That is, all children conceal in order to dictate others' opinions of them, but they aspire to project different images via concealment (Fu et al 2007; Lee et al. 1997). In a study of parents' instrumental lying to children (i.e. lying to ensure their own interests), Heyman et al. (2013) found that Chinese parents lie to their children more frequently than U.S parents, which the authors attribute to power-distance and expectations of child obedience.

In sum, based on existing research, I do not expect the role of autonomy desire in the concealment process to vary across individualist and collectivist societies. However, differences in the conditions under which autonomy is desired, as well as social norms dictating the desirability of certain matters, means of comportment, and power structures, can yield changes in the specific matters actors conceal and who they conceal from.

\section{Scope Conditions}

A theoretical approach rarely explains the totality of a phenomenon. It is therefore useful to delineate the scope of the present theory, and to be explicit about what forms of concealment the model does, does not, and cannot explain.

Building from my assumptions, the scope of the model is restricted to the following abstract conditions:

- Situations that include a dyad or small group consisting of two types of actors, ego and alter. 
- Ego and alter are able communicate with one another.

- Ego decides whether to attempt concealment based on their desires, beliefs, and opportunities.

Beyond these abstract scope conditions, I discuss several limitations of my model that are of particular interest to social scientists who study concealment.

The model does not explain deceiving the self. Individuals fall prey to various cognitive biases — such as self-deception — that affect our interpretations and engagement with the world in many important ways. There is a large literature explaining this phenomenon (Trivers 2000), so instead of presenting a detailed overview, I mention four reasons why my model does not incorporate self-deception. First, it is difficult to claim that deceiving the self stems from a desire for autonomy. This is because autonomy, as defined here, is the freedom from control of others, and self-deception is targeted at the ego themselves. Second, it is also problematic to claim that individuals evaluate whether to conceal information from themselves. Even if something similar to an evaluation exists, it likely occurs automatically and preconsciously (Balcetis 2008). Third, it is hard to conceptualize skill as it pertains to self-deception. For example, it is unclear whether an individual requires a theory of mind about themselves in order to conceal accurately. Fourth, in my definition of concealment, the alter does not need to be aware of nor desire that the information is being kept from them. In contrast, during self-deception, since the self is both the ego and the alter, the alter is complicit in the act of concealment. Although the present model does not extend to self-deception, concealment and self-deception may nonetheless be related. Research indicates that self-deception helps ameliorate internalized social sanctions (e.g., shame and guilt) that often accompany concealment (Tenbrunsel and Messick 2004; VonHippel and Trivers 2011). 
The model does not explain compulsive lying. While compulsive lying prevents an alter's access to information and requires skill at withholding information, it is not driven by the desire for autonomy, since individuals are motivated to lie for the sake of lying. For compulsive liars, the process by which the effectiveness of concealment is evaluated may not be present, or may operate differently from what is specified here (e.g., evaluations may not reference autonomy desire) (Verschuere and Hout 2016).

The model explains certain types of mundane concealment. We rarely tell coworkers what type of toothpaste we used to brush our teeth, and we subject (almost) no one to the minutia of our inner narratives (Simmel 1906). Where do all of these little failures to disclose fit into the present theory? Many such things are withheld for reasons unrelated to the desire for autonomy. Rather, withholding is done to keep from taxing oneself and others with what would be constant revelations. Such forms of concealment fall outside the scope of my theory.

But there are other little or seemingly inconsequential things that we conceal in order to get people to have less control over our goals, actions, and views of the world, like withholding an impolite remark so as to not seem rude. These kinds of things — as inconsequential as they may be - fall within the realm of my theory, with one caveat. We know, empirically, that routinized behavior and heuristic decision-making are more likely when the stakes are low (Kahneman 2011). Therefore, when concealing relatively unimportant matters, individuals may be making a less deliberative decision. The less consequential the matter and its concealment, the less individuals are going to weigh the costs and benefits, consider alternatives, and appraise both the situation and their skill as a concealer, reducing the predictive validity of my model.

Likewise, the DBO assumption may need to be relaxed for individuals who have learned to readily conceal given a particular situation. With practice, even very strategic and 
deliberative decisions, such as choosing a dominant chess move, can become automatic (Kahneman 2011). If an ego encounters situations that allow them to hone their skill at appraising and executing concealment, such decisions may become more associative and automatic. In such cases, given that automatic decision-making yields outcomes similar to deliberative decision-making (Dijksterhuis et al. 2006), I do not expect the predictions of my overall model to change.

The model explains some types of third-party concealment. Is concealment on behalf of someone else — such as keeping someone else's secrets - part of my theoretical framework? There are two ways to think about this issue. The first is that third-party concealment lies outside the scope of the model. If you are keeping secrets on behalf of another person, you do not desire autonomy, and neither will the act of concealment generate autonomy for you.

Yet, there are some types of third-party concealment that fit within the scope of the model. To the extent that a third party wants you to keep a secret on their behalf, they become the ego, and the present theory is able to account for their motivations and decisions regarding concealment over a matter. In other words, the third party wants you to keep the secret because they want autonomy and think that your secrecy is the best way to achieve it. However, in this case, you are still the one executing the concealment-controlling leakage and carrying the cognitive and emotional load of the concealment attempt. In this scenario, two people occupy the role of the ego at different points in the concealment process. This explanation accounts for the sharing and delegation that characterizes third-party secrets: two people split the role usually occupied by one. Indeed, empirical findings show that individuals are more likely to keep a secret for another person to the extent that they identify with that person (Slepian and Greenaway 2018). 
The model cannot completely account for group concealment. Autonomy desire is a key reason why individuals seek out secret organizations or collude with others (Simmel 1950). However, group concealment involves disclosure and a surrendering of autonomy to other group members who share the secret (Simmel 1950; Gambetta and Przepiorka 2019). The simultaneous loss and gain of autonomy that accompanies group secrets involves additional social processes beyond autonomy desire — such as trust and cooperation — that determine if group concealment will emerge and reproduce (Gambetta 2011; Gambetta and Przepiorka 2019). Thus, I view autonomy desire as a necessary (but not sufficient) condition for the emergence secret societies and organizations.

The model accounts for other concealment motivations. What about concealment that is motivated by such considerations as relationship maintenance, altruism, or self-interest? After all, in everyday life, we often conceal information to get what we want, because it might make other people feel bad, or because it may jeopardize a relationship that is important to us (Gneezy 2005). The short answer is that these motivations do not produce concealment in the absence of autonomy. In most cases, altruistic and other-regarding motivations must be accompanied by the desire for autonomy in order for an attempt at concealment to occur.

Here is an illustrative scenario. Suppose you and your best friend work together, and you want to collaborate on a project with a third colleague, whom your best friend dislikes. You are fairly positive that your friend will be upset when they learn about the collaboration, and that this will also introduce tension to the workplace. You want to avoid both of these outcomes because you care about your friend (altruism), and because you value workplace harmony (relationship maintenance). Given this, there are a number of ways you could go about managing the situation. You can choose to not collaborate with your friend's nemesis, or ask for your friend's approval before attempting the collaboration. Both of these instances 
would allow your friend's anticipated or actual reactions to guide your actions, and you would forego autonomy in your decision to collaborate for altruism. Alternately, you could decide to collaborate no matter what, but be honest and engage with your friend in a frank and supportive discussion about the benefits of collaborative projects with colleagues, or mediate a conversation between you, the new collaborator, and your friend, that may allow the three of you to move past this decision in a positive way. These choices are also motivated by concern for your friend and the workplace environment, allow you some behavioral autonomy (you still decide whether to collaborate), but also let your friend independently influence how the situation resolves (they could become indignant or decide to end the friendship). In other words, once you disclose the information, you lose autonomy and control over the situation. Still another possibility, is to conceal the collaboration entirely. You would choose concealment over any of the previous options not because you are altruistic or care about workplace dynamics (you do but these motivations remain constant across all scenarios). Instead, you would conceal because despite your intentions and efforts, you do not trust your friend to react the way you want them to upon disclosure. Your friend's reactions could end the collaboration, bring tension to the workplace, or lead them to think that you are a bad coworker or friend. In this case, concealment grants you autonomy over your actions, autonomy in defining the type of friend you are, and autonomy in regulating workplace dynamics.

Finally, self-interest is the most widely cited motivation for concealment (Goffman 1959; Gottfredson and Hirschi 1990; Ariely 2012). It is intuitive to think of self-interest and autonomy as complimentary motivations (e.g., Shapiro 2005), so I do not discuss the two at length here. It is worth noting, however, that I treat autonomy for the sake of self-interest as theoretically identical to autonomy for the sake of altruism or relationship-maintenance. In other words, self-interest in the absence of autonomy desire will not motivate concealment. 
In sum, many forms of altruistic, self-interested, or relationship-focused behavior are consistent with my theory. This is because many decisions that produce concealment are a function of desire for autonomy.

\section{Discussion and Conclusion}

In the present article, I proposed a theory of concealment that engages situational aspects of concealment, and draws upon work across the social sciences. My model highlights the role of desire for autonomy in concealment, and builds upon prior theories and definitions of concealment. The relation between group level norms and stigma on the one hand, and individual desire to conceal information on the other, echoes Goffman's (1963) work on the presentation of self. Because autonomy is often desired in order for the ego to pursue their own ends and avoid interventions or sanctions by alters, my model is consistent with problem-oriented views of concealment as a self-regarding behavior that enables problem behaviors (Gottfredson and Hirschi 1990; Grigoryeva 2018). I also draw on the privacy literature to identify how privacy designations affect individual claims to autonomy and the ability to keep matters concealed (Nippert-Eng 2010; Anthony et al. 2017). My model offers a way to think about these disparate literatures in a single framework.

To fill in what was missing in sociological approaches to concealment, I drew on research outside of sociology. In particular, the choice to ground my model in the desire for autonomy is informed by the psychological research (Desi and Ryan 1985b; Stattin and Kerr 2000; Jensen et al. 2004). The concept of theory of mind is incorporated from developmental psychology (e.g., Talwar and Lee 2002). The interplay between ego ability and alter suspicion owes to Buller and Burgoon (1996). And the link between power and concealment echoes agency theory (Ross 1973). By tapping into the social science literature on concealment, I produced a broad generative theory that accounts for the types of concealment 
of interest to sociologists, and overcomes issues-imprecision, normative bias, and tautology—inherent to other theoretical approaches.

This synthesis improves our understanding of concealment in three ways. First, it allows social scientists to evaluate many types of concealment—including self-interested, altruistic, antisocial, and legitimate concealment—within a single theoretical framework. Second, it provides a theoretical scaffolding for the new and innovative research being done on concealment in sociology (Kitts 2003; Cowan 2014; Cowan and Baldassarri 2018): a multilevel model of how autonomy considerations help explain patterns of information spread, group ignorance, relationship quality, and the spread of norms and attitudes. Third, by building on concepts shared by concealment research from across the social sciences, my model helps generate a dialog between previously disparate literatures.

\section{Beyond Synthesis}

Though I consider the synthetic aspect of my model to be an important contribution in its own right, the present theory also offers several new ways of conceptualizing concealment. The new way of theorizing about the concealment process that I propose has implications for future work on concealment, and — as novel theoretical propositionsrequire empirical scrutiny. I review each implication below, and suggest directions for future research.

First, in specifying the desire for autonomy—rather than self-interest, altruism, or impulsivity — as a necessary condition for concealment, I theoretically highlight autonomy seeking as central to the spread of information across individuals, networks, and cultures. In terms of empirical research, this suggests that groups that place greater value on autonomy with regard to a matter, may experience misinformation about the matter, as well as narrowly focused flows of information. Likewise, individuals and groups that restrict others' autonomy will be less informed, and more likely to suffer from biased and incomplete information. My 
recommendation for future tests of this model are to engage dimensions of autonomy when researching concealment. This can be done by (a) including previously validated measures of autonomy found in psychology (e.g., Deci and Ryan 1985a), and (b) choosing empirical cases where autonomy is contested among actors or autonomy relations change over time — such as relationships between parents and adolescents (Grigoryeva 2018).

Second, I show that concealment intentions, attempts, and success—and the interrelations between the three-depend on meso- and macro-level factors such as power, privacy and ownership designations, norms about concealment, and structural opportunities. Prior theory and empirical work has conflated attempts at concealment with success of concealment (Gneezy 2005; Ariely 2012; Kitts 2003; Cowan 2014). The present model helps determine whether (the lack of) knowledge is a function of attempts at concealment, success of concealment attempts, or both. The model also helps identify which meso- and macrolevel conditions affect each stage of the concealment process. An example illustrates how norms sanctioning a matter decouple the motivation to conceal from the success of concealment: abortion clinics do not advertise their services openly, giving patients increased chances of concealing an abortion. One tactic of the anti-abortion movement is to draw public attention (and shame) to those who visit abortion clinics. Even though individuals who want to get an abortion in anti-abortion communities may be as (or more) motivated to conceal their abortions as individuals in pro-abortion communities, their attempts may be less successful because of the increased public scrutiny of abortions allowed and tolerated in antiabortion communities. If we equate success with attempt, we would erroneously infer that individuals who live in anti-abortion states are less motivated to conceal than they really are. My recommendation is that future work should empirically decouple concealment attempts from success. 
Third, I specify concealment as a process that unfolds over time. My model indicates that the duration of concealment informs its success, the emotional and cognitive costs associated with concealment, as well as researchers' ability to measure concealment. Secrets intended for a long period of time may be trickier to sustain, and therefore prone to failure. Alternately, given that two types of secrets are told at the same rate, shorter secrets are less likely to be observed empirically than longer ones. Finally, the emotional toll concealment extracts from the ego, increases with the length of concealment. In the extreme, irreversible concealments - where the ego is unable to reveal information despite the desire to revealmay be taxing because any emotional or informational distance that was established between the ego and the alter cannot be reversed. Going forward, the length of a secret should be considered by concealment research.

Fourth, I offer a value-free definition of concealment that does not treat concealment as inherently adaptive or maladaptive (Gottfredson and Hirschi 1990). This implies that survey research structured in a way that treats concealment as a problem behavior should be referenced with caution, and that value-neutral operationalizations of concealment are an important goal for future research. At the same time, it is imperative to acknowledge that concealment can have negative or unanticipated consequences for both the ego and the alter. Concealment can create emotional distance between individuals, prevent valuable or helpful interventions by alters, decrease cognitive capacity via cognitive load, or appear beneficial in the short—but not long—run. In other words, the benefits and costs surrounding concealment, for both the self and others, are varied and situationally dependent.

Another point involves the issue of studying concealment more generally. How does one evaluate my model, given that the object of study is something that's hidden, and often stigmatized? I outline two possible methods. First, experiments remain the "gold standard" for theory testing. Both factorial survey experiments (FSE) and lab experiments enable 
researchers to empirically disentangle the effects of dyad- and group-level factors that are, in reality, highly correlated. An added strength of FSEs is that they allow researchers to manipulate features of the social world that are difficult to manipulate in a lab environment (e.g., norms regarding teen sex). For these reasons, FSEs offer a promising means of testing my propositions. Second, diary studies, where alters and egos keep diaries for a specified amount of time, can shed light on complex processes of communication and concealment between actors who interact in real-world settings and have long-standing relationships in a way that may not be accessible via experimental methods.

Finally, while this paper is about concealment, and not disclosure, the two concepts are related and can be interpreted as dimensions of one overarching process of information management. I focus solely on concealment out of the concern for having sufficient space to explain my theoretical approach. I will, however, outline ways to think about disclosure in light of the present paper. First, disclosure complements concealment: when a person is first aware that a piece of information can be revealed or concealed, a lack of desire for autonomy, insufficient opportunity for concealment, negative appraisals of one's skill in concealing, or alternatives to concealment will encourage someone to disclose concealable information. Disclosure can also end a period of concealment, in part to alleviate the cognitive load and control of the self that are required for successful concealment (Buller and Burgoon 1996; Gombos 2006; Small 2017). Finally, depending on the situation, decisions to disclose can be subject to automatic thinking, as well as "slow" deliberation (Small 2017).

\section{Conclusion}

In the preceding pages, I offered a theory of concealment that covers a broad range of behaviors including secret keeping, deception, obfuscation, and omission. Concealment affects nearly all facets of social life and delineates the contours of our known realities. To the extent that it is connected to autonomy, concealment is crucial to how we understand and 
comport ourselves both as members and as outsiders of society. Up to this point, research on concealment existed without a general theoretical model. It is my hope that the current paper will serve as a foundation for a general and systematic accumulation of knowledge on concealment. 


\section{APPENDIX A}

\section{Autonomy: Some background}

Although autonomy has been central to multiple aspects of sociological inquiry (Simmel 1950; Burt 1980; Fowler 2006), the most robust research program on autonomy exists in social psychology (Desi and Ryan 1985b). The concept of autonomy is rooted in the philosophies of Greek political thinkers, as well as enlightenment philosophers Emmanuel Kant, David Hume and John Stuart Mill. Originally, the concept meant "independence and the ability to govern oneself without domination" (Reindal 1999). Kant proposed that autonomy is the ability to reflect and make rational choices. This has been referred to as rationalistic definition of autonomy (Aviram 1995; Reindal 1999). In contrast, the so-called volunteerist view of autonomy, attributed to Hume and Mill, defines autonomy as the ability to realize one's wants and desires. Both rationalistic and volunteerist views, as well as most early discussions of autonomy at the group level, characterize autonomy in absolute termsautonomy with regard to all external social influences, and across all situations (Simmel, 1950; Reindal 1999). Consequently, autonomy has been viewed as asocial and individualizing (Simmel, 1950; Dove et al., 2017). Psychologists Deci and Ryan (1985b) draw on these traditions, but attempt to steer the term away from criticisms of autonomy as overly atomized and positivist. Incorporating social psychological work on authenticity (Chen 2019), Deci and Ryan define autonomy as "self-determination" — not an absence of external influences or pressures, but rather the ability to either enact or endorse choices that are in line with one's core values and authentic self (Ryan and Deci 2006). Here, authenticity means something a person takes ownership of, an action that is intrinsically motivated and "congruent with the whole self" (Ryan and Deci 2006). This definition recasts autonomy as subjective, and something that arises out of the social roles and identities that individuals adopt (Chen 2019). 
According to Deci and Ryan (1985b), the endorsement dimension of autonomy indicates that being controlled by others can be considered autonomy as long as the person believes that (a) being controlled is in their best interest, or (b) the person can obtain ends that reflect their "true" selves. For Desi and Ryan, non-conscious acts can be autonomous as long as they can be reflectively endorsed. That is, if the reason for an action's automaticity is that the action so completely aligns with an actor's values and preferences that they need not debate the decision to act in the moment (acting automatically), but would agree with it upon reflection, then that action can be considered autonomous. Likewise, Ryan and Deci stress that endorsement, rather than the attribution of motivation to the self, works best as criteria for autonomy, since individuals tend to wrongfully attribute initial causes of their actions (Ryan and Deci 2006). Altogether, Deci and Ryan's (1985b) self-determination theory has enjoyed wide application in social psychology (Standage et al. 2005; Ng et al. 2012; Chen et al. 2015) and their General Causality Orientations Scale is widely used and highly-validated (Deci and Ryan 1985a; Deponte 2004; Olesen 2011; and many others).

My definition, while retaining elements of Deci and Ryan's original conceptualization, offers a more situational and less value-oriented approach to autonomy. I propose that autonomy is a person's subjective evaluation of whether they are free from the control or influence of a given alter with regard to a given matter. This situational definition of autonomy implies that an actor can simultaneously be (and/or desire to be) autonomous in one situation, but also experience (and/or desire) dependence and control in other situations. The following example highlights the key difference between my definition of autonomy and that of Deci and Ryan. If an ego decides to surrender control over a matter to an alter, Deci and Ryan would interpret the controlled behavior as autonomous because the ego authentically agreed to surrender control. According to my definition, ego's initial choice to surrender control to the alter is autonomous, but to the extent that ego's behavior is thereafter 
controlled by the alter, ego's behavior will not be autonomous. The degree of autonomy in this situation is determined by two ongoing countervailing choices: ego's continued choice to be controlled on the one hand, and the actual control that ego is subject to.

Another feature of my definition that is distinct from (though not necessarily contrary to) Deci and Ryan (1985b) is that, while autonomy is a subjective assessment by an individual actor, it also depends on the relationship between the actor and the alter, as well as the matter. In other words, there is an interplay between individual-specific interpretations of the situation and relational-structural properties of the situation. While actors may have individual tendencies or preferences for autonomy across situations, the perceptions and desire for autonomy vary greatly depending on the situation in which the alter and ego interact. This distinction adds to prior general causality orientation research by highlighting within-individual as well as between-individual differences in perceptions of autonomy and autonomy desire (general causality orientation scales are predominantly used to examine between-individual propensities for autonomy). The definition of autonomy as specificexisting in relation to a focal alter and a particular matter-implies that autonomy in situation $\mathrm{X}$ may not translate to autonomy in situation Y, and may, in fact, increase ego's vulnerability to being controlled in situation Y.

The final point of departure between my definition of situational autonomy and Deci and Ryan's (1985b) definition is that situational autonomy is not necessarily tied to one's moral compass. You can perceive autonomy — lack of external control from a focal othereven with regard to enacting a matter which you do not endorse on a moral level; behaving in a way that is incongruent with your core values can still be autonomous. Likewise, even if you agree with the reasons behind external control (e.g. organizational rules and regulations) you can still perceive your choices and behaviors as controlled by an outside force. 


\section{References}

Adler, Patricia, and Peter Adler. 2015. Constructions of Deviance: Social Power, Context, and Interaction, Eighth Edition. US: Nelson Education.

Afifi, Tamara D., Loreen N. Olson, and Christine Armstrong. 2005. "The Chilling Effect and Family Secrets." Human Communication Research 31(4): 564-598.

Afifi, Walid A., and Judith L. Weiner. 2004. "Toward a Theory of Motivated Information Management." Communication Theory 14(2): 167-190.

Ajzen, Icek. 2005. Attitudes, Personality, and Behavior. UK: McGraw-Hill Education.

Akers, Ronald L. 1991. "Self-Control as a General Theory of Crime." Journal of Quantitative Criminology 7(2): 201-211.

Alexander, Michelle. 2010. The New Jim Crow: Mass Incarceration in the Age of Colorblindness. New York, NY: The New Press.

Anthony, Denise, Celeste Campos-Castillo, and Christine Horne. 2017. "Toward a Sociology of Privacy." Annual Review of Sociology 43: 249-269.

Ariely, Dan. 2012. The (Honest) Truth About Dishonesty. New York, NY: Harper Collins Publishers.

Aviram, Aharon. 1995. "Autonomy and Commitment: Compatible Ideals." Journal of Philosophy of Education 29, 1: 61-73.

Bacharach, Samuel B. 1989. "Organizational Theories: Some Criteria for Evaluation." Academy of Management Review 14(4): 496-515.

Baddeley, Alan D. 2000. "The Episodic Buffer: A New Component of Working Memory?" Trends in Cognitive Science 4: 417-423.

Baghai, Katayoun. 2012. "Privacy as a Human Right: A Sociological Theory." Sociology 46(5): 951-965.

Balcetis, Emily. 2008. "Where the Motivation Resides and Self-Deception Hides: How Motivated Cognition Accomplishes Self-Deception." Social and Personality Psychology Compass 2(1): 361-381.

Becker, Howard S. 1963. Outsiders. New York, NY: Simon and Schuster.

Becker, Gary S. 1998. Accounting for Tastes. Cambridge, MA: Harvard University Press.

Beckett, Katherine. 1997. Making Crime Pay: The Politics of Law and Order in the Contemporary United States. New York: Oxford University Press.

Buller, David B., and Judee K. Burgoon. 1996. "Interpersonal Deception Theory." Communication Theory 6(3): 203-242. 
Burt, Ronald S. 1980. "Autonomy in a Social Topology." American Journal of Sociology 85, 4: 892-925.

Burt, Ronald S. 2009. Structural Holes: The Social Structure of Competition. Cambridge, MA: Harvard university press.

Chen, Serena. 2019. "Authenticity in Context: Being True to Working Selves." Review of General Psychology 23, 1: 60-72.

Chen, Beiwen, Jasper Van Assche, Maarten Vansteenkiste, Bart Soenens, and Wim Beyers. 2015. "Does Psychological Need Satisfaction Matter When Environmental or Financial Safety Are at Risk?" Journal of Happiness Studies 16, 3: 745-766.

Chirkov, Valery, Richard M. Ryan, Youngmee Kim, and Ulas Kaplan. 2003. "Differentiating Autonomy from Individualism and Independence: A Self-Determination Theory Perspective on Internalization of Cultural Orientations and Well-Being." Journal of personality and social psychology 84, no. 1 (2003): 97.

Cohen, Lawrence E., and Marcus Felson. 1979. "Social Change and Crime Rate Trends: A Routine Activity Approach." American Sociological Review 44(4): 588-608.

Cohen, Percy S. 1968. Modern Social Theory. New York: Basic Books.

Collins, Randall, and Michael Makowsky. 1972. The Discovery of Society. New York: Random House.

Cook, Karen S. 1987. Social Exchange Theory. Newbury Park, CA: Sage Publications.

Cowan, Sarah K. 2014. "Secrets and Misperceptions: The Creation of Self-Fulfilling Illusions." Sociological Science 1: 466-492.

Cowan, Sarah K., and Delia Baldassarri. 2018. "“It Could Turn Ugly": Selective Disclosure of Attitudes in Political Discussion Networks." Social Networks 52: 1-17.

Cullen, Francis T., John P. Wright, and Kristie R. Blevins. 2008. Taking Stock: The Status of Criminological Theory. Volume 15. New Brunswick, NJ: Transaction Publishers.

Dawe, Alan. 1973. “The Underworld of Erving Goffman.” British Journal of Sociology 24(2): 246-253.

Deci, Edward L., and Richard M. Ryan. 1985a. "The General Causality Orientations Scale: Self-Determination in Personality." Journal of Research in Personality 19(2): 109-134.

Deci, Edward L., and Richard M. Ryan. 1985b. Intrinsic Motivation and Self-Determination in Human Behavior. New York: Plenum.

Deponte, Antonella. 2004. "Linking Motivation to Personality: Causality Orientations, Motives and Self-Descriptions." European Journal of personality 18, 1: 31-44.

Dewey, John. 1922. Human Nature and Conduct. London: Allen and Unwin. 
Dijksterhuis, Ap, Maarten W. Bos, Loran F. Nordgren, and Rick B. Van Baaren. 2006. "On Making the Right Choice: The Deliberation-Without-Attention Effect." Science 311(5763): 1005-1007.

Dove, Edward S., Susan E. Kelly, Federica Lucivero, Mavis Machirori, Sandi Dheensa, and Barbara Prainsack. 2017. "Beyond Individualism: Is There a Place for Relational Autonomy in Clinical Practice and Research?." Clinical Ethics 12, 3: 150-165.

Emerson, Richard M. 1962. "Power-Dependence Relations." American Sociological Review 27(1): 31-41.

Emerson, Richard M. 1976. "Social Exchange Theory." Annual Review of Sociology 2(1): 335-362.

Erat, Sanjiv, and Uri Gneezy. 2012. "White Lies." Management Science 58(4): 723-733.

Evans, Jonathan St BT. 2008. "Dual-Processing Accounts of Reasoning, Judgment, and Social Cognition." Annual Review of Psychology 59: 255-278.

Fales, Evan, and Barry Markovsky. 1997. "Evaluating Heterodox Theories." Social Forces 76(2): 511-525.

Fowler, Bridget. 2006. "Autonomy, Reciprocity and Science in the Thought of Pierre Bourdieu." Theory, Culture \& Society 23, 6: 99-117.

$\mathrm{Fu}$, Genyue, Fen Xu, Catherine Ann Cameron, Gail Heyman, and Kang Lee. 2007. "CrossCultural Differences in Children's Choices, Categorizations, and Evaluations of Truths and Lies." Developmental Psychology 43, 2: 278-293.

Gambetta, Diego. 2011. Codes of the Underworld: How Criminals Communicate. Princeton, NJ: Princeton University Press.

Geis, Gilbert. 2000. On the Absence of Self-Control as the Basis for a General Theory of Crime: A Critique. Theoretical Criminology 4(1):35-53.

Gervais, Jean, Richard E. Tremblay, Lyse Desmarais-Gervais, and Frank Vitaro. 2000. Children's Persistent Lying, Gender Differences, and Disruptive Behaviors: A Longitudinal Perspective. International Journal of Behavioral Development, 24(2): 213-221.

Gilovich, Thomas D., and Dale W. Griffin. 2010. "Judgment and Decision Making.” Pp. 542588 in Handbook of Social Psychology Vol. 1, 5th edition, edited by S. Fiske, D. and L. Gardner. Hoboken, NJ: Wiley and Sons.

Gneezy, Uri. 2005. "Deception: The Role of Consequences." American Economic Review 95(1): 384-394.

Goffman, Erving. 1959. The Presentation of Self in Everyday Life. London: Harmondsworth. 
Goffman, Erving. 1963. Stigma: Notes on the Management of Spoiled Identity. New York, NY: Simon and Schuster.

Goffman, Erving. 1974. Frame Analysis: An Essay on the Organization of Experience. Cambridge, MA: Harvard University Press.

Gombos, Victor A. 2006. "The Cognition of Deception: The Role of Executive Processes in Producing Lies." Genetic, Social, and General Psychology Monographs 132(3): 197214.

Gottfredson, Michael R., and Travis Hirschi. 1990. A General Theory of Crime. Stanford University Press.

Grigoryeva, Maria S. 2018. "Strategic Action or Self-Control? Adolescent Information Management and Delinquency." Social Science Research 72: 225-239.

Guess, Andrew, Jonathan Nagle, and Joshua Tucker. 2019. "Less Than You Think: Prevalence and Predictors of Fake News Dissemination on Facebook." Science Advances 5(1): eaau4586.

Hahn, Ulrike. 2011. "The Problem of Circularity in Evidence, Argument, and Explanation." Perspectives on Psychological Science 6(2): 172-182.

Hedstrom, Peter. 2005. Dissecting the Social: On the Principles of Analytical Sociology. Cambridge, UK: Cambridge University Press.

Hedström, Peter, and Peter S. Bearman. 2009. The Oxford Handbook of Analytical Sociology. Oxford, UK: Oxford University Press.

Heyman, Gail D., Anna S. Hsu, Genyue Fu, and Kang Lee. 2013. "Instrumental Lying by Parents in the US and China." International Journal of Psychology 48, 6: 1176-1184.

Hirschmann, Albert O. 1970. Exit, Voice, and Loyalty: Responses to Decline in Firms, Organizations, and States. Cambridge, MA: Harvard University Press.

Hofstede, Geert. 1984. Culture's Consequences: International Differences in Work-related Values. Beverly Hills, CA: Sage, 1984.

Jensen, L. A., Arnett, J. J., Feldman, S. S., \& Cauffman, E. 2004. "The Right to Do Wrong: Lying to Parents Among Adolescents and Emerging Adults." Journal of Youth and Adolescence, 33(2): 101-112.

Kachanoff, Frank J., Donald M. Taylor, Julie Caouette, Thomas H. Khullar, and Michael JA Wohl. 2019. "The Chains on All My People Are the Chains on Me: Restrictions to Collective Autonomy Undermine the Personal Autonomy and Psychological WellBeing of Group Members." Journal of Personality and Social Psychology 116, 1: 141.

Kahneman, Daniel. 2011. Thinking, Fast and Slow. New York, NY: Farrar, Straus and Giroux. 
Kitts, James A. 2003. "Egocentric Bias or Information Management? Selective Disclosure and the Social Roots of Norm Misperception." Social Psychology Quarterly 66(3): 222237.

Lammers, Joris, Janka I. Stoker, Floor Rink, and Adam D. Galinsky. 2016. "To Have Control Over or to Be Free from Others? The Desire for Power Reflects a Need for Autonomy." Personality and Social Psychology Bulletin 42, 4: 498-512.

Lawler, Edward J., and Jeongkoo Yoon. 1993. "Power and the Emergence of Commitment Behavior in Negotiated Exchange." American Sociological Review 58(4): 465-481.

Lee, Kang, Catherine Ann Cameron, Fen Xu, Genyao Fu And, and Julie Board. 1997. "Chinese and Canadian Children's Evaluations of Lying and Truth Telling: Similarities and Differences in the Context of Pro-and Antisocial Behaviors." Child Development 68, 5: 924-934.

Leotti, Lauren A., Sheena S. Iyengar, and Kevin N. Ochsner. 2010. "Born to Choose: The Origins and Value of the Need for Control." Trends in Cognitive Sciences 14, 10: 457463.

Lizardo, Omar, Robert Mowry, Brandon Sepulvado, Dustin S. Stoltz, Marshall A. Taylor, Justin Van Ness, and Michael Wood. 2016. "What are Dual Process Models? Implications for Cultural Analysis in Sociology." Sociological Theory 34(4): 287-310.

Marwick, Alice E., and Danah boyd. 2014. "Networked Privacy: How Teenagers Negotiate Context in Social Media." New Media and Society 16(7): 1051-1067.

Marx, Gary T., and Glenn W. Muschert. 2007. "Personal Information, Borders, and the New Surveillance Studies." Annual Review of Law and Social Science 3: 375-395.

Matsueda, Ross L., and Maria S. Grigoryeva. 2014. "Social Inequality, Crime, and Deviance." Pp. 683-714 in Handbook of the Social Psychology of Inequality, edited by. E. Lawler, J. McLeod, and M. Schwalbe. New York, NY: Springer Publishing.

Mazar, Nina, On Amir, and Dan Ariely. 2008. "The Dishonesty of Honest People: A Theory of Self-Concept Maintenance." Journal of Marketing Research 45(6): 633-644.

Mead, George Herbert. 1934. Mind, Self and Society (Volume 111). Chicago, IL: University of Chicago Press.

Michailidou, Georgia; Valentina Rotondi. 2019. "I'd Lie for You” European Economic Review 118: 181-192.

Miller, Susan L., Kay B. Forest, and Nancy C. Jurik. 2003. "Diversity in Blue: Lesbian and Gay Police Officers in a Masculine Occupation." Men and Masculinities 5(4): 355-385.

Miller, Thomas G. 1986. "Goffman, Positivism and the Self." Philosophy of the Social Sciences 16(2): 177-195. 
Mollborn, Stefanie. 2017. Mixed messages: Norms and Social Control Around Teen Sex and Pregnancy. Oxford, UK: Oxford University Press.

Ng, Johan YY, Nikos Ntoumanis, Cecilie Thøgersen-Ntoumani, Edward L. Deci, Richard M. Ryan, Joan L. Duda, and Geoffrey C. Williams. 2012. "Self-determination Theory Applied to Health Contexts: A Meta-Analysis." Perspectives on Psychological Science 7, 4: 325-340.

Nippert-Eng, Christena E. 2010. Islands of Privacy. Chicago, IL: University of Chicago Press.

Olesen, Martin Hammershøj. 2011. "General Causality Orientations Are Distinct from but Related to Dispositional Traits." Personality and Individual Differences 51, 4: 460-465.

Reinarman, Craig. 1994. "The Social Construction of Drug Scares." Pp. 92-105 in Constructions of deviance: Social Power, Context, and Interaction, edited by P. Adler and P.Adler. US: Nelson Publishing.

Reindal, Solveig Magnus. 1999. "Independence, Dependence, Interdependence: Some Reflections on the Subject and Personal Autonomy." Disability \& Society 14, 3: 353367.

Ritzer, George. 1996. Sociological Theory, 4th Edition. New York, NY: McGraw-Hill.

Ross, Stephen A. 1973. The Economic Theory of Agency: The Principal's Problem. The American Economic Review, 63(2): 134-139.

Rossman, Gabriel. 2014. "Obfuscatory Relational Work and Disreputable Exchange." Sociological Theory 32(1): 43-63.

Rote, Wendy M., and Judith G. Smetana. 2015. "Acceptability of Information Management Strategies: Adolescents' and Parents' Judgments and Links with Adjustment and Relationships." Journal of Research on Adolescence 25(3): 490-505.

Ryan, Richard M., and Edward L. Deci. 2006. "Self-regulation and the Problem of Human Autonomy: Does Psychology Need Choice, Self-Determination, and Will?." Journal of personality $74,6:$ 1557-1586.

Schalet, Amy T. 2011. Not Under My Roof: Parents, Teens, and The Culture Of Sex. Chicago, IL: University of Chicago Press.

Schilke, Oliver, and Gabriel Rossman. 2018. "It's Only Wrong if It's Transactional: Moral Perceptions of Obfuscated Exchange." American Sociological Review 83(6): 10791107.

Schwarz, Norbert. 1990. Feelings as Information: Informational and Motivational Functions of Affective States. New York, NY: The Guilford Press.

Shapiro, Susan P. 2005. Agency Theory. Annual Review of Sociology, 31: 263-284. 
Simmel, Georg. 1906. "The Sociology of Secrecy and of Secret Societies." American Journal of Sociology 11(4): 441-498.

Simmel, Georg. 1950. The Sociology of Georg Simmel. Vol. 92892. New York, NY: Simon and Schuster.

Simpson, Sally S. 2013. "White-Collar Crime: A Review of Recent Developments and Promising Directions for Future Research." Annual Review of Sociology 39: 309-331.

Slepian, Michael L., Jinseok S. Chun, and Malia F. Mason. 2017. "The Experience of Secrecy." Journal of Personality and Social Psychology 113(1): 1-33.

Slepian, Michael L., and Katharine H. Greenaway. 2018. "The Benefits and Burdens of Keeping Others' Secrets." Journal of Experimental Social Psychology 78: 220-232.

Slepian, Michael L., and James N. Kirby. 2018. "To Whom Do We Confide Our Secrets?" Personality and Social Psychology Bulletin 44(7): 1008-1023.

Small, Mario Luis. 2017. Someone to Talk To. Oxford, UK: Oxford University Press.

Standage, Martyn, Joan L. Duda, and Nikos Ntoumanis. 2005. "A Test of Self-Determination Theory in School Physical Education." British Journal of Educational Psychology 75, 3: 411-433.

Stattin, Häkan, and Margaret Kerr. 2000. "Parental Monitoring: a Reinterpretation." Child Development 71(4): 1072-1085.

Stouthamer-Loeber, Magda. 1986. "Lying as a Problem Behavior in Children: A Review." Clinical Psychology Review 6(4): 267-289.

Stryker, Sheldon. 1980. Symbolic Interactionism: A Social Structural Version. Menlo Park, CA: Benjamin/ Cummings.

Suddaby, Roy. 2010. "Editor's Comments: Construct Clarity in Theories." Academy of Management Review 35(3): 346-357.

Sweet, Paige L. 2019. "The Sociology of Gaslighting." American Sociological Review 84(5): 851-875.

Talwar, Victoria, and Angela Crossman. 2011. "From Little White Lies to Filthy Liars: The Evolution of Honesty and Deception in Young Children." Advances in Child Development and Behavior 40: 139-179.

Talwar, Victoria, and Kang Lee. 2002. "Development of Lying to Conceal a Transgression: Children's Control of Expressive Behavior During Verbal Deception.” International Journal of Behavioral Development 26(5): 436 - 444.

Talwar, Victoria, and Kang Lee. 2011. "A Punitive Environment Fosters Children's Dishonesty: A Natural Experiment." Child Development 82(6): 1751-1758. 
Tenbrunsel, Ann E., and David M. Messick. 2004. "Ethical Fading: The Role of SelfDeception in Unethical Behavior." Social justice research 17 (2): 223-236.

Thomas, William I., and Dorothy S. Thomas. 1928. The Child in America: Behavior Problems and Programs. New York, NY: Knopf.

Thye, Shane R., Jeongkoo Yoon, and Edward J. Lawler. 2002. "The Theory of Relational Cohesion: Review of a Research Program." Pp. 217-244 in Advances in group process, edited by S. Thye and E. Lawler. Oxford, UK: Elsevier.

Triandis, Harry C. 1995. Individualism and Collectivism. Boulder, CO: Westview.

Triandis, Harry C., Peter Carnevale, Michele Gelfand, Christopher Robert, S. Arzu Wasti, Tahira Probst, Emiko S. Kashima et al. 2001."Culture and Deception in Business Negotiations: A Multilevel Analysis." International Journal of Cross Cultural Management 1, 1: 73-90.

Trivers, Robert. 2000."The Elements of a Scientific Theory of Self-Deception." Annals of the New York Academy of Sciences 907(1): 114-131.

Tversky, Amos, and Daniel Kahneman. 1979. "Prospect Theory: An Analysis of Decision Under Risk." Econometrica 47(2): 263-291.

Verschuere, Bruno, and Willem in' t Hout. 2016. "Psychopathic Traits and Their Relationship with the Cognitive Costs and Compulsive Nature of Lying in Offenders." PloS One 11(7): e0158595.

Von Hippel, William, and Robert Trivers. 2011. "The Evolution and Psychology of SelfDeception." Behavioral and Brain Sciences 34(1): 1.

Vrij, Aldert, and Samantha Mann. 2001. "Telling and Detecting Lies in a High-Stake Situation: The Case of a Convicted Murderer." Applied Cognitive Psychology: The Official Journal of the Society for Applied Research in Memory and Cognition 15(2): 187-203.

Weber, Max. 2009. The Theory of Social and Economic Organization. New York, NY: Simon and Schuster.

Wherry, Frederick F., Kristin S. Seefeldt, and Anthony S. Alvarez. 2019. "To Lend or Not to Lend to Friends and Kin: Awkwardness, Obfuscation, and Negative Reciprocity." Social Forces 98(2): 753-793. 


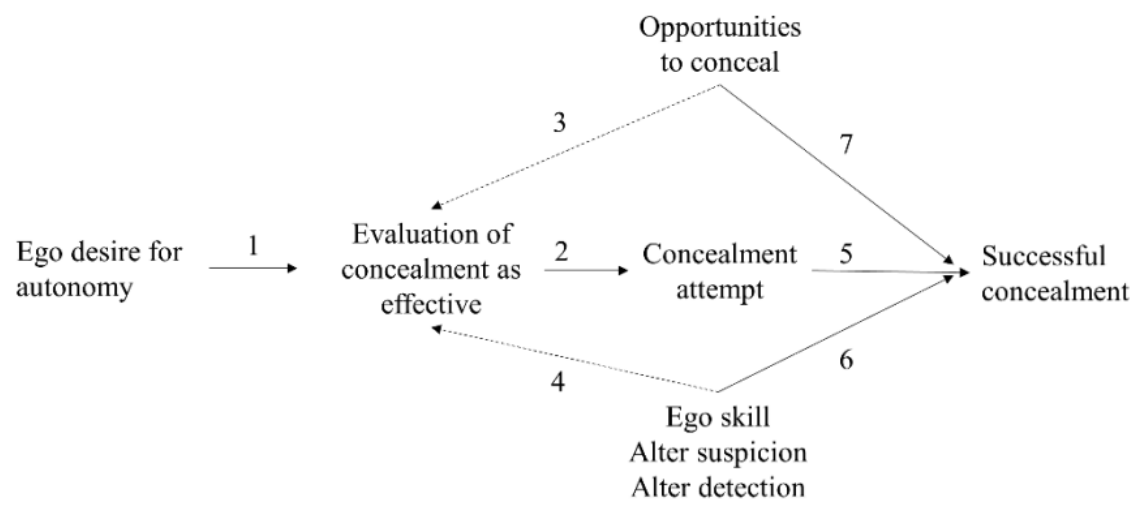

Figure 1. Dyadic Model of Concealment as Autonomy Seeking 


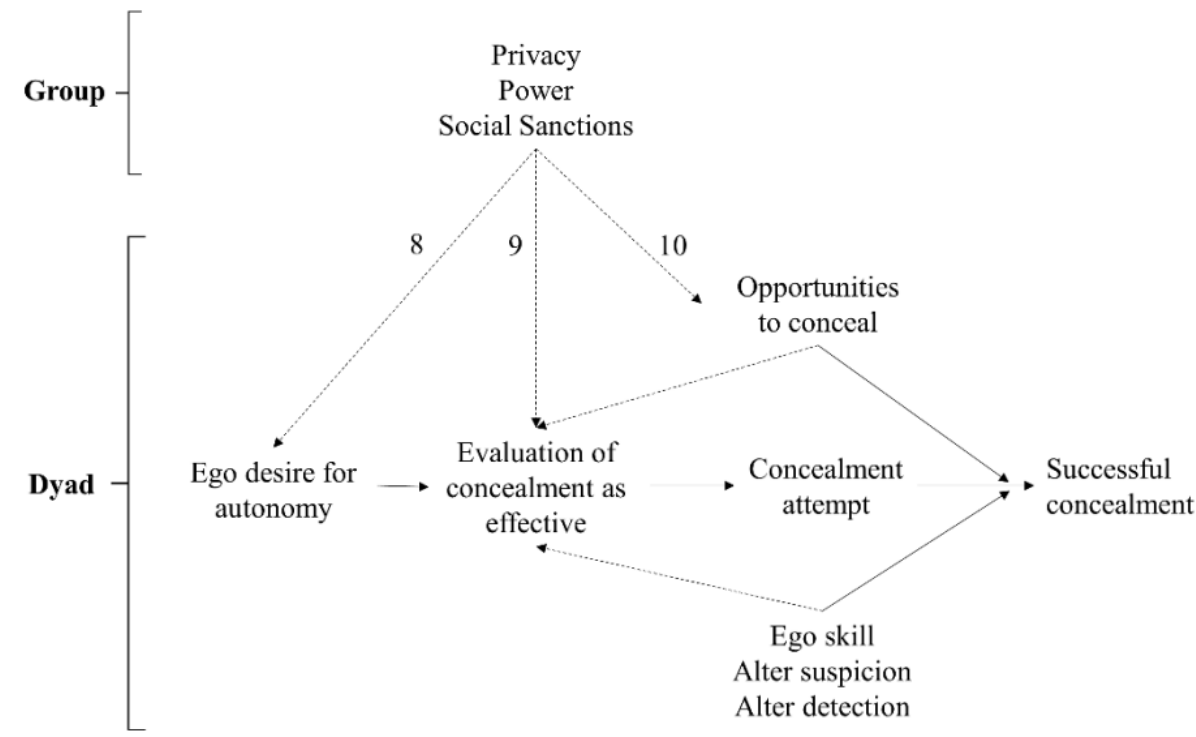

Figure 2. Multi-level Model of Concealment as Autonomy Seeking 